\title{
La relación asimétrica Europa y Tercer Mundo: un tema weberiano en debate
}

\author{
H. C. F. Mansilla*
}

\begin{abstract}
Resumen
El estudio hace una breve reseña de la evolución contemporánea en el Tercer Mundo, usando como referente lo que Max Weber llamó la excepcionalidad de la evolución europea, que ha representado la gran peculiaridad alrededor del mundo: la especialización de roles y funciones, la racionalización de la vida cotidiana y la aplicación de estos principios a las esferas del saber, el derecho, la administración y la economía, y que han tenido que ver directamente con la generación de prosperidad a largo plazo y en favor de amplias capas sociales. En cambio, los procesos de modernización en el Tercer Mundo intentan crear un orden original y propio, que ayude a establecer una identidad sólida y distinguible de otros regímenes político-sociales. Pero el resultado global es un modelo de mediocridad e imitación. ¿Es esta imitación del paradigma occidental una ley obligatoria de la evolución?
\end{abstract}

La interpretación de esta relación asimétrica está orientada por la prudencia y basada en la experiencia, que juzga de acuerdo a lo probable, factible y razonable y que no se exime de la necesidad de emitir juicios valorativos.

\section{Palabras clave}

Civilización, cultura, occidente, racionalidad instrumental, Europa, Tercer Mundo, socialismo y democracia.

\begin{abstract}
The study makes a brief review of the contemporary evolution in the Developing Countries by using as a reference what Max Weber called the exceptionality of the European evolution, which has represented the great peculiarity around the world: the specialization of roles and functions, the rationalization of daily life and the application of these principles to the fields of knowledge, law, administration and economics, and that have had to do directly with the generation of prosperity in the long term and in favor of wide social layers. On the other hand, the processes of modernization in the Developing Countries try to create an original and own order that helps to establish a solid identity distinguishable from other politic-social regimes. But the global result is a model of mediocrity and imitation. Is this imitation of the western paradigm a mandatory law for evolution?

The interpretation of this asymmetric relation is guided by the prudence and based on the experience which judges according to what is probable, feasible and reasonable and that does not exempt the need of emitting appraising judgments?
\end{abstract}

\section{Key words}

civilization, culture, western, instrumental rationality, Europe, Developing Countries, socialism and democracy.

Forma sugerida de citar: Mansilla, HCF. 2010. La relación asimétrica Europa y Tercer Mundo: un tema weberiano en debate. Universitas 13 julio/diciembre, Quito: Ed. Abya-Yala. Pp. 15-40.

Doctor en Ciencias Políticas y profesor de la Universidad de Alemania. Vicepresidente de la Academia de Ciencia de Bolivia, Profesor ne la Universidad de Sao Leopoldo -Brasil. 


\section{La existencia del paradigma occidental}

Para comprender la evolución contemporánea en Asia, África y América Latina es conveniente realizar un breve ejercicio dentro de una disciplina clásica: la Filosofía de la Historia. Debido a que el desarrollo de Europa Occidental a partir del siglo XVI modificó considerablemente el desenvolvimiento interno de muchas sociedades extra-europeas (se destruyeron modelos civilizatorios originales y peculiares, como en tierras americanas), no podemos prescindir, por más superficial que sea, de un análisis de lo que Max Weber llamó la excepcionalidad de la evolución europea, la que impuso paulatinamente al planeta entero un tipo determinado de evolución en casi todos los campos de la vida humana. Debido al desprestigio de las concepciones universalistas, a la relevancia momentánea de las teorías relativistas y, sobre todo, a los designios autonomistas de los propios países del Tercer Mundo, ya no podemos admitir fácilmente un esquema único de la historia universal, con sus secuencias de periodos forzosos y un solo telos racional de la evolución, pero estamos obligados a considerar el enorme peso y la significación que para nuestra época aun posee la excepcionalidad de la historia europea.

En un extenso estudio sobre temas weberianos, Wolfgang Schluchter señaló que el ocuparse de problemas de la historia universal no presupone el postular una determinada teoría de evolución universal o una filosofía de la historia (Schlutchter, 1979: 5-21). Hasta se puede proponer una secuencia de periodos evolutivos, pero esta operación sólo tendría una función hipotética y una intención heurística, en el sentido de tratar de aprender algo más mediante procedimientos siempre precarios y provisorios. La preocupación por la filosofía de la historia no siempre está inspirada por intereses estratégicos (Berlin, 1992: 72-96); se puede indagar por una curiosidad científica exenta de impulsos materiales o también por el anhelo de un mejor autoconocimiento, que es probablemente la inclinación prevaleciente entre los intelectuales del Tercer Mundo.

Un sentido común guiado críticamente nos aconseja proceder evitando los extremos interpretativos, sin claudicar en la intención de comprender la complejidad de los fenómenos estudiados y sus connotaciones a veces desagradables con respecto a nuestras convicciones más íntimas. No se puede, por ejemplo, aseverar enfáticamente que las categorías de la razón occidental son universales 
y obligatorias, pero tampoco podemos decretar la pluralidad e igualdad liminares de 'razones' locales y temporales. Algunos fenómenos son probablemente irreductibles a un solo metacriterio de comprensión general, pero las historias de las sociedades humanas han sido edificadas por seres similares a nosotros, y así podemos, mediante un esfuerzo de empatía, reconstruir paso a paso su arquitectura, comprender sus arcanos y penetrar en el sentido de sus dogmas y sus dioses.

No hay duda, por otra parte, de que la teoría de la incomparabilidad e inconmensurabilidad de los fenómenos socio-históricos posee una función muy profana y prosaica: estabilizar y vigorizar identidades nacionales y grupales devenidas precarias por el avance de la civilización europea y hoy por la globalización; es decir, cuando el impulso paradigmático irradiado por Europa Occidental y América del Norte amenaza con diluir todas las características específicas e identitarias de las tradiciones específicas. Este enfoque particularista, que suena tan plausible, progresista y hasta simpático, tiene un rol instrumental de primer rango: poner en duda el modelo occidental para asegurar la vigencia del orden tradicional propio, con sus estamentos privilegiados, sus costumbres irracionales (aunque cómodas), sus prácticas autoritarias y sus intereses bien establecidos.

A propósito califico a la filosofía de la historia como una disciplina clásica, pues lo clásico es lo que permanece vigente durante largos periodos temporales y adquiere así una fuerza normativa de primer rango. Concepciones actuales, que rechazan precisamente la idea de lo clásico y lo normativo en general, como las numerosas variantes del relativismo axiológico, las escuelas posmodernistas, deconstructivistas y hermenéuticas y los cultural studies, son ciertamente muy importantes en determinados momentos y, sobre todo, poseen una influencia notable dentro del ámbito académico que sería necio el ignorar, pero probablemente no pasen la prueba del tiempo y las edades. Estas concepciones postulan la imposibilidad de establecer jerarquías y gradaciones dentro de los modelos civilizatorios, presuponiendo que estos son, en el fondo, tan buenos unos como otros. Este relativismo impide la comprensión de la excepcionalidad del desarrollo europeo y, paradójicamente, dificulta el entendimiento de sus luces y sus sombras. En su campo preferido de análisis (los sistemas sociohistóricos extra-europeos) entorpece la comprensión de los aspectos negativos 
de los mismos y encubre el estudio de aquellos factores que han impedido hasta hoy una evolución razonable en dilatadas porciones de Asia, África y América Latina.

Por lo tanto: hay que evitar el extremo de sostener la existencia de leyes obligatorias de la evolución histórica, con etapas y secuencias prefijadas que todas las sociedades, más temprano que tarde, están destinadas a reproducir. Y, al mismo tiempo, hay que guardarse de postular el carácter único, incomparable e inconmensurable de los distintos modelos civilizatorios, que no podrían ser traducidos a un idioma general que abarcase la comprensión de todos. Jürgen Habermas nos recordó que el concepto mismo de la incomparabilidad e inconmensurabilidad de una cultura es autocontradictorio, como el relativismo a ultranza. Un interlocutor competente puede adoptar o, por lo menos, entender el horizonte de interpretación de los otros interlocutores, lo que conforma una especie de intercambio recíproco de perspectivas, y en medio de esta dinámica genera una interpretación provisoria, compartida intersubjetivamente y que no está predeterminada necesariamente por factores etnocéntricos o culturales (Habermas y Derrida, 2006:63). El mero hecho del intercambio de perspectivas invalida la afirmación de la irreductibilidad completa. Y son los habitantes del Tercer Mundo los que cada día se acercan a lo Otro por excelencia para ellos (la cultura dominante metropolitana occidental) y toman de ella comportamientos e inventos, religiones y prejuicios, juguetes y armas, comprendiendo, aunque sea parcial y defectuosamente, para qué sirven esos artefactos y esas normas. Es lícito, obviamente, acariciar serias dudas en torno a este optimismo habermasiano con respecto al núcleo y a los alcances de la razón comunicativa, puesto que esta concepción es de índole general y abstracta. Su vigencia es dificultosa y sólo parcial en el complejo y profano campo de la praxis política cotidiana. Pese a ello el enfoque de Habermas nos muestra que, sin renunciar a su propia verdad, un interlocutor puede seguir un debate racional que no termina en un consentimiento hacia las opiniones y los intereses del otro, pero que resulta brindando un disenso productivo. $Y$ este es, en el fondo, el idioma común de comprensión: una alta estima recíproca de formas de vida y de culturas extrañas a uno mismo. Esto diluye el fanatismo que significa eliminar toda comunicación y socava la "comprensión fundamentalista de uno mismo" (Habermas, 1997: 46, 56-58). 
La cultura europea occidental 'no' ha sido básicamente similar a las otras civilizaciones del mundo, sino, como lo entrevió Max Weber, el desarrollo de Occidente ha representado la gran $-\mathrm{y}$ exitosa- peculiaridad a nivel mundial, la que requiere de un esfuerzo explicativo mayor (cfr. Weber 1920/1921: 1-4). Hay pocas dudas acerca de lo positivo de esta evolución caracterizada (no sólo por Max Weber) como excepcional: la especialización de roles y funciones, la racionalización de la vida cotidiana y la aplicación de principios racionalistas a las esferas del saber, el derecho, la administración y la economía. Empezando por el espacio puritano-protestante y siguiendo por otras confesiones religiosas en Europa y América del Norte, la esfera de la profesión, el trabajo y la vocación se transformó en una existencia reglamentada racionalmente hacia el mayor rendimiento, lo que fomentó la acumulación del capital y el incremento constante de la productividad. Este modelo civilizatorio ha sido proclive al individualismo, a la protección de los derechos de libertad y propiedad y a una actitud básicamente sobria y pragmática con respecto al Estado, sus símbolos y dignatarios (cfr. Weber, 1920/1921: 1-4). Todo esto produjo un ámbito civilizatorio cualitativamente más exitoso que el resto de los sistemas sociales en todo el planeta.

Pero tampoco se puede pasar por alto los aspectos negativos de la civilización occidental. El de mayores consecuencias ha sido el predominio de la racionalidad parcial de los medios sobre la razón global de los fines: los mecanismos instrumentales se imponen por encima de los objetivos de largo alcance. Como señaló Herbert Marcuse al criticar el enfoque weberiano, este sistema dominado por la racionalidad instrumental puede llegar a convertirse en una 'burocracia total', en la cual la legitimidad del orden político se reduce al funcionamiento adecuado de los subsistemas de racionalidad instrumental (cfr. Weber: 1-4), lo que significaría el fin de una democracia genuina, basada en principios humanistas. La modernidad se transformaría en un conjunto de subsistemas bien aceitados, y uno de ellos sería una burocracia con excelente desempeño técnico. La equiparación de la racionalidad técnico-instrumental con la razón política haría superfluo cualquier intento de configurar la esfera político-institucional según los preceptos de una razón global de los fines. El libre albedrío (cfr. Bieri, 2001), la discusión de alternativas políticas serias (y no 
meramente personales) y hasta los esfuerzos teóricos por comprender y mejorar el mundo se revelarían como ilusorios.

\section{La 'jaula de hierro' y el desencanto con el paradigma occidental}

La racionalización de la vida cotidiana y de los procesos económicos y administrativos puede generar ciudadanos cortados todos a la misma medida e imbuidos de los mismos principios, quienes, precisamente por ello, resultan a la postre más manejables por el poder central. Existe, entonces, el peligro de un nuevo totalitarismo: más suave en su aplicación, más tecnificado en sus procedimientos, pero más extendido y más penetrante: similar a la "jaula de hierro de la servidumbre" (cfr. Mitzman, 1976: 212, 215-217, 220 sq., 268) que previó Max Weber para la sociedad racional-burocrática del futuro. Como escribió Wolfgang Mommsen con mucho fundamento, es probable que los sistemas sociales basados exclusivamente en la racionalidad instrumental requieran de un complemento irracional, por ejemplo el predominio de un caudillo carismático; estos sistemas, donde prevalece una tendencia legalista-positivista, dan lugar paradójicamente a procedimientos decisionistas, entremezclados por emociones antirracionales y antidemocráticas (cfr. Mommsem, 1974: 21-43; ibíd, 1974: 44-71; ibíd:126).

En el mundo moderno la superioridad técnica de la administración burocrática sobre cualquier otra hace ilusorio todo modelo genuino de igualitarismo y socialismo, lo que nos hace percibir también - de manera más sobria y críticalos límites de todo régimen democrático. La imagen de la jaula de la servidumbre -como la manifestación más evidente de lo negativo de la modernidades un indicio claro de la visión crítica que Weber tenía del mundo dominado por la razón instrumental. Otra huella en este sentido es la nostalgia que Weber, partidario de la abstención de juicios evaluativos, expresó acerca de la desaparición de los ‘últimos y más sublimes valores' de la vida pública; estos se habrían refugiado en la mística y en la intimidad, proceso inevitable porque el mundo moderno pierde sus aspectos mágicos y religiosos (Weber, 1968: 338).

Yendo más allá, numerosos autores — como los miembros de la Escuela de Frankfurt- sostuvieron que el modelo civilizatorio basado en el racionalismo 
y la Ilustración contiene 'gérmenes autodestructivos'; el desencanto del mundo, previsto por Max Weber, genera el desamparo del individuo, pero esto es sólo el primer paso. Y si el mundo pierde toda connotación mágico-religiosa, se transforma en una simple cantera para los designios humanos de utilización material e inmediata, lo que puede conducir (y, en realidad ya condujo) a la crisis ecológica y a los desarreglos medio-ambientales. Siendo esta temática muy conocida (cfr. Barman, et. al., 1996), aquí nos limitaremos a analizar algunas de sus connotaciones para la idea del progreso permanente derivadas del racionalismo histórico.

Estas magnas concepciones del racionalismo han sido impugnadas tempranamente. Ya en el siglo XVIII Johann Gottfried Herder y Giambattista Vico pusieron en duda el optimismo doctrinario contenido en las teorías del progreso histórico linear y el carácter universalista que se arrogaron los pensadores de la Ilustración al tratar las variadas culturas del mundo (Berlin, 1980: 80-129). El universalismo derivado de la exitosa evolución europea -cuyos representantes más conocidos son el Marqués de Condorcet, G. W. F. Hegel, Karl Marx y Auguste Comte- ha sido permanentemente cuestionado mediante argumentos de mucho peso y profundidad (cfr. Mitias, 1991:5-15; Ramose: 75-87) Pero es indudable que también muy pronto se percibieron las desventajas del relativismo axiológico, histórico y político, que van desde un voluntarismo elitista hasta un nacionalismo agresivo. Vico mismo, aunque propugnaba un pluralismo cultural, no aceptaba la incomparabilidad e inconmensurabilidad de los modelos civilizatorios; por medio de la empatía, sostenía Vico, podemos comprender y juzgar los fundamentos y los valores de las culturas ajenas. Basado en este autor, Sir Isaiah Berlin mostró que se puede construir una síntesis fructífera entre principios éticos universales y valores culturales particulares, entre los conceptos básicos del racionalismo humanista y la defensa romántica de las peculiaridades nacionales o regionales (Berlin, 1991: 297-325, 305). Esto es un ejemplo de un sentido común guiado críticamente.

En este contexto también se puede afirmar que, en el fondo, no ha existido un progreso genuino en el campo religioso. La transición desde cultos locales politeístas, originados por obra de la simple casualidad evolutiva, hasta religiones monoteístas de pretensión universal (con sus revelaciones dogmáticas, sus creencias codificadas en textos y sus jerarquías sacerdotales), conlleva el peli- 
gro de la ortodoxia, la tentación de combatir las 'otras' religiones equivocadas y la terminación de la tolerancia en cuestiones de fe. Según Jan Assmann, en las religiones 'primarias', o sea en las politeístas, no habría espacio para verdades sostenidas dogmáticamente, entre otras razones porque no existiría una frontera inequívoca entre deidades y fenómenos naturales (tesis igualmente poco exacta y muy generalizante). Los credos 'secundarios', los monoteístas, habrían creado las diferencias entre verdad y falsedad teológica y la necesidad de combatir esta última (Assmann, 2007). Este teorema de Assmann, que se encuadra dentro de la confusa voluntad de deconstrucción hoy en boga, ya fue anticipada por pensadores de la Antigüedad clásica (como el emperador Juliano el Apóstata) y filósofos de la Ilustración: el monoteísmo fue considerado tempranamente como intolerante, dogmático y autoritario, con serias consecuencias sobre la vida política e intelectual. Hay que añadir, en passant, que pese a sus notables logros práctico-políticos, el politeísmo no generó una gran producción teológica ni fomentó destrezas lógico-conceptuales, por lo que sin el monoteísmo el desarrollo de la filosofía, como la conocemos hoy, habría sufrido carencias y retrasos. Y, simultáneamente, hay que relativizar la tesis tan general de que los politeísmos son intrínsecamente más tolerantes que cualquier monoteísmo. Los súbditos de los imperios asirio, azteca, maya e incaico acariciaban probablemente una opinión más matizada sobre este asunto, sobre todo si tenían que fungir como víctimas de las muchas ceremonias donde se sacrificaban seres humanos en honor de las deidades tutelares.

\section{Limitaciones del relativismo histórico}

Conviene recordar que el relativismo axiológico choca con límites y limitaciones, y que estas últimas son valiosas a la hora de preguntarse por la persistencia de ciertos valores de orientación y determinadas metas de desarrollo. Estos valores y estas metas no han sido probablemente universales en su origen, pues son creaciones de la cultura occidental. Su adopción por casi todos los pueblos y grupos humanos del planeta - como los aspectos centrales de la modernización material- nos ponen en guardia contra cuestionamientos muy difundidos pero indefendibles en torno a la diversidad total de los modelos evolutivos y, sobre todo, en torno a la presunta imposibilidad de compararlos y 
confrontarlos entre sí y emitir juicios estimativos sobre sus dispares cualidades. No es superflua la mención de que la religión cristiana jugó un rol preponderante en la historia occidental al contribuir a edificar valores de orientación que no son sustituibles o intercambiables por otros; se trata de normativas que no son fáciles de ser sometidas al juego de la deconstrucción relativista (cfr. Herder, 2002). Jürgen Habermas sostuvo que el actual Estado de Derecho, liberal, democrático y secularizado, se alimenta de fundamentos prepolíticos que él mismo no ha creado ni puede garantizar, y que estos fundamentos son de origen religioso o provenientes de antiguas fuentes de moralidad colectiva. El Estado de Derecho, una de las creaciones más excelsas de Occidente, no puede reducirse a aspectos procedimentales, electorales y políticos en sentido estricto, es decir a elementos 'inmanentes' de su propio acervo, por más importantes que estos sean. En esta constelación hay que mencionar las dimensiones que son fines en sí mismos, como la solidaridad, el reconocimiento que va más allá de lo formal, la estética pública, el campo del amor y la amistad. La religión, dice Habermas, aparece entonces como la fuerza que ha mantenido viva 'la intuición de culpa y redención' y la fuente de sensibilidad para comprender una existencia malograda, el fracaso de los proyectos personales de vida y la deformación de las relaciones humanas (Habermas, 2005: 15-37 especialmente $31 \mathrm{sq})$. En la larguísima disputa entre el cristianismo y la filosofía griega se han ido formando nuestras concepciones centrales sobre la autonomía individual, la dignidad humana y la justicia social, que se derivan de la semejanza entre Dios y el Hombre, y que por ello no pueden ser sometidas sin más al relativismo de turno. Por otra parte la religión permanece como impulso activo y creativo en las esferas intelectual y ética porque han surgido dudas sensatas en torno a la confiabilidad de la razón (Ibíd, 47).

Con respecto a casi todos los campos de la actividad humana se puede aseverar que ha habido tanto progreso como regresión, y que la idea de un avance lineal permanente es una cosa de perspectiva y creencia. Pongo a propósito 'casi' porque me asaltan dudas cuando pienso en la medicina, los transportes y comunicaciones y la praxis política. Precisamente en este terreno no ha surgido una alternativa realmente diferente, seria y duradera que significara una concurrencia al modelo desarrollado en Europa Occidental (cfr. Roche, 2007). Por ello y de todas maneras es indispensable recordar lo siguiente: el racionalismo 
griego, las filosofías estoica y escéptica, el cristianismo, el renacimiento y el despliegue de la ciencia en las naciones occidentales de Europa han producido una amalgama histórica única, una cultura fundamentalmente diferente a la de los otros continentes, y sólo ella ha engendrado la actual concepción de la superioridad e inconfundibilidad del individuo y sus derechos personales (cfr. Muguerza et al, 1989; Donely, 1989; Lamprecht, 1999). Aun considerando toda la barbarie cometida con ayuda de la razón instrumental, no se puede soslayar la gran conquista de Occidente: los derechos humanos, el orden democrático, el pluralismo de valores, la secularización, la moral universalista y el espíritu científico. Es bueno y necesario el cuestionar la civilización occidental y relativizar sus logros - lo que, además, es una moda con réditos académicos tangibles-, pero es necio el negar los avances de esa civilización occidental que han hecho la vida del Hombre más llevadera y más plena en gran parte del planeta.

Existen, obviamente, innumerables impugnaciones y relativizaciones de las tesis weberianas. Y también teorías que complementan la concepción weberiana, iluminando aspectos y perspectivas que a primera vista parecen marginales. En un libro de amplia divulgación y por ello lleno de generalizaciones y exageraciones, Jared Diamond sostuvo que el éxito mundial y permanente de la civilización europea se debió en última instancia a factores geográficos y climáticos, que se tradujeron en resistencia genética mayor y en mejor inmunización contra enfermedades y plagas que en otras culturas. Estos factores, en conjunción con los histórico-culturales, dieron lugar a la racionalidad como la concebimos hoy (la ciencia y la técnica), al debate abierto en escala socialmente significativa, a la gran filosofía desde Grecia hasta la Ilustración y, como corolario, a la democracia (Diamond, 2003: pasim)

También es adecuado consignar otra teoría complementaria de esta corriente conceptual. Según David S. Landes, el desarrollo desigual de las naciones tuvo que ver con la configuración de los derechos de propiedad. Sólo en Europa Occidental y América del Norte se dio de manera persistente una tendencia histórica de respeto y protección a la propiedad de las clases medias y hasta de los estratos no privilegiados de la sociedad; en otras latitudes y en el llamado despotismo oriental el gobierno de turno podía confiscar y redistribuir las propiedades sin muchos miramientos y sin que la 'opinión pública' respectiva se sorprendiera. Era lo usual: los bienes de los súbditos representaban el botín que 
era repartido según los caprichos y los planes del detentador del poder, sin que existiesen regulaciones que impidieran esas arbitrariedades. Al no poder disfrutar de la riqueza acumulada o no poder legarla con certeza a los herederos, se disipaba la intención de planificar las inversiones y se debilitaba el potencial de innovación. Tales circunstancias no favorecían el aumento de la productividad ni tampoco el incremento de la riqueza social como totalidad. El Estado de Derecho y la seguridad institucional han tenido que ver directamente con la generación de prosperidad a largo plazo y en favor de amplias capas sociales (Landes, 1998, passim). Esta posición concuerda, en lo general, con la teoría del despotismo oriental de Karl A. Wittfogel (1977). En un amplio estudio que compara la Inglaterra isabelina con la Rusia moscovita, Richard Pipes llegó a la conclusión de que la estabilidad y protección de la propiedad privada es esencial para el florecimiento de las libertades políticas y civiles; los regímenes 'patrimonialistas' (Winckelmann, 1956: vol. I: 133-139; vol II: 588-632; Rodinson, 1987: 180-189), que no distinguen entre soberanía estatal y propiedad privada, tienden a ordenamientos sociales de índole dictatorial o, por lo menos, arbitraria. "El derecho de propiedad no garantiza en sí y de por sí los derechos y libertades civiles. Pero, históricamente, ha sido el mecanismo más efectivo para asegurar ambas cosas" (Pipes, 2002: 357; cfr Pipes, 2002: 15, 355-371). La consolidación de los derechos de propiedad para todos los ciudadanos y el establecimiento de garantías contra las numerosísimas posibilidades confiscatorias del Estado constituyen piedras angulares en la construcción del Estado de Derecho y del sistema democrático, y aparentemente estas líneas evolutivas se dieron con la profundidad necesaria sólo (o inicial y sostenidamente) en Europa Occidental.

Hannah Arendt ya había criticado la fácil identificación de propiedad con posesión y de éstas con riqueza, así como la equiparación de falta de propiedad con pobreza (Arendt, 1981: 60-62). La existencia de un ámbito privado con derechos consolidados es indispensable para la construcción de la esfera pública; esta es impensable sin el correlato de un espacio privado con suficientes derechos y garantías para los individuos. Esta dialéctica entre lo público y lo privado, que es esencial para el florecimiento de la política en sentido enfático, desaparecería, según Arendt, en concepciones como la marxista; una sociedad totalmente sin 
clases (y sin disparidades y divergencias) haría superflua toda actividad política, que es una discusión y negociación de diferencias (Ibíd.: 313 sq.)

\section{Carencias de los modelos existentes}

Una de las primeras críticas al socialismo realmente existente, y una de las más sólidas y clarividentes, fue la realizada por un adversario del marxismo, Max Weber. El socialismo sería, según Weber, la culminación (y no la superación) de un desarrollo histórico tendiente a una burocracia fuerte y global, evolución que conllevaría la desaparición de la libertad, la autodeterminación y el pluralismo cívico ${ }^{1}$. No hay duda, por otra parte, de que los modelos colectivistas de organización social pueden tener muchos aspectos positivos, que van desde sistemas de solidaridad inmediata hasta una dotación estable de una sólida identidad grupal ${ }^{2}$, pero estos modelos prescriben la subordinación del individuo bajo los imperativos de la organización social y son contrarios, por lo tanto, a la concepción de una dignidad ontológica superior de la persona frente a las estructuras colectivas. Los modelos colectivistas tienden en primer término, por simple lógica de interactuación exitosa, a la preservación y al engrandecimiento de sus unidades políticas, lo que exige la movilización casi irrestricta de todos los recursos (incluidos los que podríamos llamar humanos) al servicio de los fines superiores de los entes colectivos. La felicidad personal de sus súbditos, el radio de actuación individual de éstos últimos - sus posibilidades de desplegar una elemental actividad política pluralista y autónoma, por ejemploy su bienestar material han sido a lo largo de la historia universal o bien resultados fortuitos de las acciones estatales o efectos sociales considerados muy a

1 Max Weber, Der Sozialismus (El socialismo) [1920], edición anotada de Herfried Münkler, Weinheim: Beltz Athenäum 1995, passim; Gernot Volger, Max Weber und der Sozialismus (Max Weber y el socialismo), en: LIBERAL (Bonn), vol. 38, № 1, febrero de 1996, pp. 111-114. brillante y exhaustivo tratado de Lutz Niethammer, Kollektive Identität. Heimliche Quellen einer unheimlichen Konjunktur (Identidad colectiva. Fuentes secretas de una coyuntura inquietante), Reinbek: Rowohlt 2000. 
menudo como un debilitamiento del poder central y de la sólida coherencia que debían caracterizar a los regímenes colectivistas. En lo que ha sido la situación habitual de los sistemas colectivistas, la libertad y la prosperidad de los individuos eran asuntos indiferentes para los poderes constituidos. Todo esto no ha sido favorable al florecimiento de derechos humanos que pueden (y a veces deben) 'contraponerse' a designios colectivos. Por su propia dinámica los modelos colectivistas no han generado a partir de sí mismos estatutos comparables a los derechos humanos actuales, que más bien son el resultado del desarrollo largo y complejo de la llamada cultura europea occidental.

Ahora bien, el hecho histórico de que los derechos humanos se hayan originado en Europa Occidental no quiere decir que las otras culturas de la Tierra no los puedan comprender y adoptar plena y cabalmente. La inmensa mayoría de los inventos tecnológicos, los descubrimientos científicos, las creaciones literarias, las costumbres y hasta los juegos se han originado en un determinado contexto civilizatorio, pero se han extendido parcialmente por el resto del planeta y han sido adoptados como propios por las más diversas culturas, las cuales no han sufrido traumas identitarios por ese hecho. A comienzos del siglo XXI -se puede aseverar-, que no ocurrirá lo mismo con otras creaciones históricoculturales como la democracia, la cultura política liberal-pluralista y el espíritu racionalista o, por lo menos, que ocurrirá con mayores dificultades.

En este contexto hay que mencionar en primer lugar la dialéctica de autonomía e imitación: la mayoría de las naciones del Tercer Mundo (y sobre todo los movimientos políticamente radicales) anhela una evolución que merezca ser llamada 'auténtica' y un ordenamiento socioeconómico que pueda ser calificado de 'autónomo'. Los procesos de modernización en el Tercer Mundo intentan crear un orden original y propio, que además del éxito material perdurable, ayude a establecer una identidad sólida y distinguible de otros regímenes político-sociales. Pero el resultado global no es un modelo de autenticidad y autonomía, sino uno de mediocridad e imitación. Con algunas honrosas excepciones los Estados del Tercer Mundo se destacan por la edificación de un modelo urbanizado e industrializado que toma sus parámetros de orientación de los países occidentales del Norte, pero este modelo ha generado al mismo tiempo una inmensa degradación del medio ambiente, un gigantismo urbano con una calidad de vida muy reducida, un crecimiento demográfico de inesperadas 
consecuencias y emigraciones masivas de dimensiones planetarias (y no todas muy positivas). El desarrollo efectivo en el Tercer Mundo puede ser calificado de mediocre por sus resultados cotidianos; en lugar de autonomía el distintivo central de la evolución es la imitación del paradigma occidental, pero como copia de segunda clase. Aquí nace la cuestión fundamental de si la imitación del paradigma occidental por casi todas las sociedades del Tercer Mundo constituye algo así como una ley obligatoria de la evolución, aunque sea de manera indirecta. Esta pregunta no puede ser respondida adecuadamente en el marco de este breve texto.

La preeminencia de la cultura europea basada en la ciencia y la democracia es reconocida como tal fuera de su lugar de origen. Es interesante observar el caso islámico porque parece que en aquel ámbito no existe ese reconocimiento de parte de sus instituciones oficiales o de sus eruditos religiosos (o sólo en grupos minoritarios). Pero la realidad es siempre más compleja. Es evidente que no hay un solo tipo de sociedad islámica; en todo el mundo musulmán coexisten al mismo tiempo diferentes modelos de organización social, distintos paradigmas culturales y muy variadas normativas políticas. Y también se da un importante Islam crítico (Arkoun, 1994; Ayubi, 1991; Benzine, 2004; Soroush, 2000), que significa una gran esperanza para un futuro democrático y una configuración racional de la vida pública. Pero asimismo se puede constatar todavía algunas tendencias vigorosas que preservan el autoritarismo cotidiano en esas sociedades. Y son precisamente estas corrientes - entre muchas otras - las que determinan el atraso evolutivo del mundo musulmán en comparación con el espíritu científico e indagatorio que prevalece en la esfera académica e intelectual de los países occidentales (pese a la continua expansión de las inclinaciones tecnocráticas). A comienzos del siglo XX, Max Weber se preguntó por qué el Islam no generó un impulso a un orden capitalista moderno, pese al universalismo de su mensaje, a sus tendencias puritanas y a sus variados rasgos racionalistas. Weber encontró que factores de primer rango, inherentes a la identidad teológicohistórica del Islam (la conexión inextricable entre las esferas religiosa y estatal y el desdén por las leyes humanas en comparación con las normas derivadas del 
Corán y la tradición), fomentaron el estancamiento de las sociedades sometidas a este credo ${ }^{3}$.

Para Hans Küng, quien trata de hacer justicia a la cultura y la historia islámicas, se puede hablar de un 'estancamiento' científico-intelectual del ámbito musulmán a partir del siglo XII, que va unido a un marcado menosprecio del individuo autónomo. Este desarrollo dificulta el debate intelectual y político y restringe el campo del pensamiento y, en última instancia, la configuración racional de la praxis (Küng, 2006: 478-483). El islamismo radical constituye una especie de reacción premoderna frente a una pérdida repentina de raíces y tradiciones, que se alimenta al percatarse sus integrantes de que la modernización $\mathrm{y}$, más aun, la globalización generan pocos ganadores y muchos perdedores.

Esta constelación de estancamiento -el tiempo petrificado- puede ser estimada como tal desde la perspectiva de Europa Occidental (o de Asia Oriental), pero también innumerables intelectuales de naciones islámicas la perciben así a causa de la baja capacidad innovativa de esas sociedades. Hoy en día, es un lugar común criticar la cultura memorística de la escuela musulmana, la poca curiosidad de sus intelectuales por el ancho mundo, la nula investigación sobre los otros continentes y la escasa producción de patentes e inventos. Se podría pensar que los países islámicos más ricos y con altos ingresos a causa de la riqueza petrolera han modificado radicalmente esta matriz de comportamiento. Pero no ha sido así. Para la productividad económica y las actividades académicas la abundancia de rentas petroleras ha sido contraproducente. En estas naciones el control y la redistribución de las rentas ha tomado una enorme importancia, lo que significa que las funciones tradicionales del Estado central y del gobierno han ganado aún más en prestigio social e importancia material, del mundo y la adaptación al mismo. Reflexiones sobre la visión de Max Weber sobre el Islam temprano), en: W. Schluchter (comp.), op. cit. (nota 25), pp. 11-124; Patricia Crone, Max Weber, das islamische Recht und die Entstehung des Kapitalismus (Max Weber, el derecho islámico y el surgimiento del capitalismo), en: ibíd., pp. 294-333; Shmuel N. Eisenstadt, Webers Analyse des Islams und die Gestalt der islamischen Zivilisation (El análisis weberiano del Islam y la configuración de la civilización islámica), en: ibíd., pp. 342-359. 
mientras que actividades alejadas de la repartición de las rentas, como todas las académicas e intelectuales, han sufrido un marcado descenso. Los 'profesionales' de la política han sido los ganadores de este nuevo desarrollo, mientras que los intelectuales y todos los que viven de ingresos salariales han perdido en relevancia. Como mediante el dinero se puede comprar todo, el trabajo, incluyendo la investigación, ha bajado en la estimación social. Las elites tradicionales del poder, que disponen sobre las rentas petroleras, han logrado consolidar sus funciones y rejuvenecer las tradiciones autocráticas (Diner, 2007: 55-58).

El Arab Human Development Report, promovido y publicado por las Naciones Unidas, brinda una visión de conjunto de los resultados obtenidos por los países árabes, el núcleo del ámbito musulmán, en los esfuerzos por un desarrollo acelerado. Los resultados son descritos como un estancamiento económico crónico, restricciones severas a las libertades públicas y políticas, un nivel educacional bajo, un marcado desinterés por el desenvolvimiento científicotécnico, una cultura política autoritaria y una vigencia sólo precaria de los derechos humanos (cfr. Diner, 2007: 55-58). Desde una perspectiva particularista se puede afirmar que los criterios de esta comparación provienen exclusivamente de Europa Occidental y América del Norte y que, por consiguiente, no pueden dar luces sobre la 'esencia' del mundo árabe. Pero la cosa no es tan simple. Las naciones árabes y musulmanas están inmersas desde hace mucho tiempo en un contexto universal globalizado, donde rigen esos parámetros. Pero mucho más importante es el hecho de que los propios habitantes de esos Estados se juzgan e identifican a sí mismos mediante un inventario de carencias y deficiencias, inventario ganado casi exclusivamente por medio de la confrontación y comparación con ese mundo occidental. Es decir: los ciudadanos de la calle miden y evalúan su sociedad con lo ya alcanzado en el ámbito occidental para conocer cómo está su desarrollo y qué deben hacer para modificarlo y mejorarlo. Y, como se sabe, las migraciones de los países árabes en dirección de Europa -el voto con los pies- es la comprobación fehaciente de que los habitantes de las 
naciones musulmanas han adoptado el paradigma occidental para decidir su destino individual ${ }^{4}$.

No se puede pasar por alto las patologías sociales generadas por la modernidad occidental, pero, como afirma Dieter Senghaas, pensador conocido por sus simpatías con posiciones izquierdistas, las ventajas de esa misma modernidad compensan de lejos sus aspectos negativos. El impulso autocrítico de la modernidad occidental (su elemento más valioso) permite detectar sus falencias y tomar los recaudos pertinentes. Según Senghaas, hoy ya no cabe defender un esencialismo cultural que proclame el carácter incomparable e inconmensurable de las sociedades autóctonas del Tercer Mundo, máxime si tal apología termina justificando prácticas autoritarias. En el campo práctico-político estaría hoy a la orden del día la 'civilización contra la propia voluntad', que se expresaría en el monopolio estatal de la violencia política, en el establecimiento del Estado de Derecho, en el control de los afectos con consecuencias sociales, en una cultura de resolución pacífica de los conflictos y en una sociedad con amplia justicia social (Senghaas, 1998: 33-46). Es probable que a causa de sus resultados globalmente benéficos estos factores se hayan convertido en criterios universales de desarrollo positivo, es decir mediante la praxis cotidiana y no por medio de una imposición teórico-doctrinaria, como también sucede a diario con mejoras en el campo de la medicina e inventos en el terreno de los transportes y las comunicaciones.

\section{Conclusiones: el sentido común frente a los imponderables del desarrollo y a las expectativas de la población}

El criterio de la vida cotidiana nos permite evaluar otros aspectos de los procesos evolutivos. Muy brevemente se mencionan aquí algunas posibilidades. En varios países africanos la gente común y corriente vive con una menor calidad de vida bajo la independencia que en la época del colonialismo europeo, sobre todo, en aquellos lugares donde la inseguridad ciudadana es muy elevada

4 Sobre la situación en América Latina cfr. Charles H. Wood / Bryan R. Roberts (comps.), Rethinking Development in Latin America, University Park: Pennsylvania State U. P. 2005. 
y donde las guerras civiles han conllevado una regresión civilizatoria. En otras naciones, el régimen monárquico y el predominio de la religiosidad tradicional, han resultado ser más benignos que la modernización acelerada dirigida por despóticos republicanos ateos, que no se preocupan por los costes humanos y sociales de los 'experimentos' que imponen a sus sociedades.

Pese a todas estas afirmaciones de carácter general, el sentido común nos recuerda que es improbable un marco explicativo unitario, que sea válido para gran parte del planeta. Parece más razonable postular tendencias 'ex negativo': establecer en forma provisional lo que no vale como generalización, lo que no tiene simultáneamente vigencia en muchos casos y lo que parece no inducir una secuencia obligatoria de acontecimientos. Así se puede afirmar, por ejemplo, que no hay una conexión causal entre felicidad y progreso; que no existe una correlación positiva entre modernización e industrialización, por una parte, y una vida bien lograda y humanamente digna, por otra. No se puede construir secuencias evolutivas obligatorias y generalizables, como la que hizo más daño en el siglo XX: la que prescribía que el desarrollo debía ir de un capitalismo condenado al estancamiento y la crisis a un socialismo próspero y humanista. Modelos socioeconómicos muy exitosos en un cierto espacio y tiempo pueden resultar un fracaso en circunstancias moderadamente diferentes. Tasas elevadas de producción y productividad no conllevan necesariamente una configuración razonable de la esfera político-institucional. Una modernización ejemplar en el campo técnico-económico no es garantía de un orden democrático y consagrado al Estado de Derecho. La aptitud de un régimen de producir índices notables de progreso material, educativo y social no depende de un modelo generalizable de desarrollo, sino de innumerables factores concretos en cada país y en cada periodo histórico. El éxito y el fracaso de una sociedad específica pueden ocurrir bajo los paradigmas de desarrollo más distintos.

Finalmente, es muy arduo el detectar una identidad nacional estable y realmente original en una época de normas universalistas y seducciones emanadas por las corrientes globalizadoras. Los postulados de originalidad tranquilizan la consciencia colectiva y constituyen el puente hacia el propio pasado y sus tradiciones, y por estos dos motivos son irrenunciables. La autenticidad de muchos regímenes nacionalistas, populistas y simplemente anti-imperialistas se agota en un folklore muy atrayente para los jóvenes desilusionados del Primer Mun- 
do. La anhelada pluralidad de los caminos de desarrollo es algo que refuerza una mentalidad colectiva que ha entrado en crisis, y aun si existe realmente, lo hace por debajo de metas normativas sustanciales prefijadas por lo alcanzado ya en las grandes naciones de Occidente, sobre todo en lo referente al nivel de vida, los éxitos materiales y los elementos determinantes contenidos en la modernidad (Mols, 1975: vol 8 No 1: 5).

La dialéctica entre autonomía e imitación se manifiesta asimismo en la importación de un aparato estatal-administrativo modernizado (por ejemplo, con fuerzas armadas dotadas de los últimos artefactos y procedimientos de esta área) en conjunción con prácticas consuetudinarias que son preservadas de la cultura política tradicional. El resultado puede ser un 'Estado anómico's, que no ofrece a sus ciudadanos un marco de orden y seguridad, sino más bien constituye una fuente de desorden. El aparato estatal pretende regular ámbitos y regiones que no controla efectivamente, y genera acciones innecesariamente violentas de sus propios agentes y sobrerreacciones inesperadas de la población. La administración pública y, sobre todo, el Poder Judicial son el origen de temor e incertidumbre, por un lado, y de pautas de comportamiento premodernas y marcadamente tradicionalistas, por otro, en lugar de irradiar una cultura moderna, predecible y previsora. En el Tercer Mundo la ola democratizadora de las últimas décadas restauró ciertamente procedimientos electorales e institucionales, pero dejó incólume la cultura política del autoritarismo y no consolidó el Estado de Derecho. El peligro global es un nuevo descontrol social y el socavamiento de las normas sociales aceptadas generalmente. Nuevamente las ventajas asociadas al desarrollo modernizante quedan debilitadas por la fuerza de la tradición o, más preocupante aun, por el impulso anómico derivado de una imitación evolutiva de segunda clase.

Un análisis de filosofía de la historia no puede prescindir de los temas y los factores que operan por detrás de los grandes acontecimientos, pero que a largo plazo son de una relevancia decisiva. Estableciendo un paralelismo con el terre-

5 El concepto proviene de Peter Waldmann, El Estado anómico. Derecho, seguridad pública y vida cotidiana en América Latina, Madrid: Iberoamericana 2006, pp. 15-19, obra llena de observaciones perspicaces sobre la realidad latinoamericana. 
no de la física, podemos afirmar que así como hay un impulso a la 'sintropía', al mantenimiento del orden, a la edificación de estructuras organizativas y a la preservación de lo existente en un momento dado, se da también la tendencia a la entropía, al desorden de las estructuras, a la disipación de la energía y a la declinación de los esfuerzos. Según Manfred Wöhlcke, las sociedades altamente complejas exhiben una inclinación manifiesta a la entropía social, es decir a la desintegración de su arquitectura central, a la dilución de sus principios organizativos, al decaimiento de los designios que mantienen en pie un orden cultural-histórico. Ejemplos dramáticos de entropía social son la crisis del medio ambiente, la explosión demográfica, las migraciones masivas, el consumo de drogas y la pobreza extrema (Wöhlcke, 1996: 15, 27,170-174). Al contrario de otros autores, Wöhlcke sostiene que la complejidad social -la notable diferenciación de roles y funciones, el alto grado de movilidad, el surgimiento de infinitos grupos secundarios y la porosidad entre capas sociales- conduce a una atomización de los intereses grupales, a la concurrencia desmedida por bienes siempre escasos (el prestigio, el dinero, los recursos naturales) y a la inseguridad permanente en cuestiones de status. De acuerdo a este teorema, el resultado global sería apocalíptico: estadios avanzados de entropía se distinguirían por el desprecio de los códigos éticos, el desdén por toda autoridad política, moral o intelectual, el predominio de la mediocridad, la dificultad de tomar decisiones y la decadencia de las normas de trato social. El derecho se convertiría en algo muy complejo y hasta contradictorio, el potencial de sanción de la sociedad decaería a niveles peligrosos y los controles de calidad se volverían ineficientes. Los juzgados estarían atiborrados de trabajo, las iglesias perderían a sus pocos fieles por seguir la moda de la secularización, las universidades bajarían de nivel y las escuelas serían presas del vandalismo. Wöhlcke asevera que este no es un escenario del futuro, sino la realidad cotidiana de algunas de las sociedades más prósperas del planeta (Ibíd, 1996: 26 sq., 231 sq.).

Aplicando esta concepción al Tercer Mundo, se puede pensar que también esta terrible constelación puede estar incluida dentro de la dialéctica de autonomía e imitación. En Asia, África y América Latina la fuerza normativa que irradian el nivel de vida y los éxitos materiales de Europa y Norteamérica es simplemente arrolladora; no se trata únicamente de un 'efecto de demostración', como lo creía la sociología convencional, sino de un 'efecto de fascinación'. 
Y esto significa que la aptitud de sopesar racionalmente ventajas y desventajas de un modelo de desarrollo y sus consecuencias queda suspendida; la razón global de los fines permanece fuera de juego. Esta es una de las posibilidades reales que dimana de la trinidad mágica de crecimiento, desarrollo y progreso cuando ésta se consagra a satisfacer las necesidades siempre imperiosas de la población, cuando suelta las amarras del sentido común, cuando se vuelve autónoma de toda reflexión sobre límites y limitaciones. Se anhela con tal intensidad el alcanzar un 'desarrollo pleno' - se lo identifica con una autonomía bien lograda- que se pierden de vista las consecuencias a largo plazo que conlleva el crecimiento económico indispensable para ello y se supone que la imitación burda, pero acelerada de la modernidad occidental es, en la práctica, el mejor camino al progreso. La racionalidad instrumental - planes de desarrollo, incentivos para acrecentar la producción y la productividad, los indicadores exitosos de crecimiento- suplantan la racionalidad de las metas y la hacen superflua.

El sentido común guiado críticamente debe evitar juicios valorativos extremos, pero sin claudicar en la intención esclarecedora: lo cual siempre es más fácil enunciar que llevar a cabo. De todas maneras parece que se puede afirmar razonablemente que no hay modelos y leyes obligatorias de desarrollo histórico, pero que el paradigma occidental a partir del siglo XVI ha influido hasta hoy de tal manera la evolución mundial que es imposible pasarlo por alto. Y esta influencia, en líneas generales, ha tenido aspectos muy positivos, que van desde la moral universalista, la democracia pluralista y el predominio del racionalismo en las actividades intelectuales. El common sense nos lleva inmediatamente a percibir lo negativo de este desenvolvimiento, que, como se sabe, alcanza desde el colonialismo europeo hasta las formas más atroces de una racionalidad instrumental eximida del control de la razón de los fines. Son juegos de intensificación, según la terminología de Gerhard Schulze ${ }^{6}$, cuyo desenlace no presagia nada bueno a nivel planetario. En gran parte del Tercer Mundo se trata, mejor de los mundos. Adónde se mueve la sociedad en el siglo XXI?), Frankfurt: Fischer 2004, p. 82 sqq., 92 sqq.- La obra de Schulze, bastante confusa en su estructura e intención, ha sido sobrevalorada indebidamente. 
por otra parte, de democracias deficientes, inestables y penetradas por factores autoritarios, populistas y nacionalistas.

Y, sin embargo, estos esfuerzos modernizantes y democratizantes son, en términos relativos, mejores que la mera continuación de regímenes tradicionales, despóticos y exentos de una dinámica de desarrollo. Una evaluación basada en el sentido común crítico puede afirmar como corolario que los productos de la racionalidad instrumental deben ser calificados de ambivalentes en alto grado y que el único criterio válido para juzgarlos es acudir al tribunal de la razón global de los fines, por más anticuado que ésto suene. Significa también admitir que valoraciones de este tipo no pueden estar enteramente cubiertas o garantizadas por datos empíricos y testimoniales y que, por consiguiente, es menester un esfuerzo interpretativo que no anule, sino que complemente los hechos registrados de la realidad inmediata. Por suerte muchos aspectos de la vida humana no pueden ser cuantificados, y por ello hay que entenderlos mediante procedimientos exegéticos. Pero esto, de ninguna manera, significa adoptar como propios los principios y las convicciones de las escuelas hermenéuticas, que, al igual que las posmodernistas, han proliferado en los últimos tiempos y promueven en el fondo una total arbitrariedad a la hora de sacar conclusiones y establecer prioridades y calidades diferenciables. Los caminos de la interpretación, siempre laboriosos y provisorios, se deberían orientar por el principio de la phronesis, la prudencia basada en la experiencia, que juzga de acuerdo a lo probable, factible y razonable y no se exime de la necesidad de emitir juicios valorativos.

\section{Bibliografía}

Arab Human Development Report (AHDR), New York: United Nations / Arab Fund for Economic and Social Development, 2002-2006.

ARENDT, Hannah Arendt (1981), Vita activa oder Vom tätigen Leben (Vida activa), Munich: Piper.

ARKOUN, Mohammed (1994), Rethinking Islam: Common Questions, Uncommon Answers Today, Boulder: Westview.

ASSMANN, Jan (2007), Die mosaische Unterscheidung (La diferencia mosaica), Munich: Hanser. 
AYUBI, Naguib (1991), El Islam politico: teorías, tradiciones y rupturas, Barcelona: Bellaterra.

BAUMAN, Zygmunt, Niklas Luhmann, Ulrich Beck y Josetxo Beriaín (comps.) (1996), Las consecuencias perversas de la modernidad, Barcelona: Anthropos.

BENZINE, Rachid (2004), Les nouveaux penseurs de l'Islam, París: Albin Michel.

BERLIN, Isaiah (1991), Giambattista Vico und die Kulturgeschichte (Giambattista Vico y la historia de la cultura), en: Berlin, Das krumme Holz der Humanität. Kapitel der Ideengeschichte (El árbol torcido de la humanidad. Capítulos de la historia de las ideas), Frankfurt: Fischer.

BERLIN, Isaiah (1980), Against the Current. Essays in the History of Ideas, Londres: Hogarth.

BIERI, Peter Bieri (2001), Das Handwerk der Freiheit. Über die Entdeckung des eigenen Willens (El oficio de la libertad. Sobre el descubrimiento de la voluntad propia), Munich: Hanser.

DIAMOND, Jared (2003), Guns, Germs and Steel: The Fates of Human Societies, New York: Norton.

DINER, Dan (2007), Versiegelte Zeit. Über den Stillstand in der islamischen Welt (Tiempo sellado. Sobre el estancamiento en el mundo islámico), Berlin: List.

DONNELY, Jack (1989), Universal Human Rights in Theory and Practice, Ithaca: Cornell University Press.

HABERMAS, Jürgen (1997), Vom sinnlichen Eindruck zum symbolischen Ausdruck. Philosophische Essays (De la impresión sensorial a la expresión simbólica. Ensayos filosóficos), Frankfurt: Suhrkamp.

HABERMAS, Jürgen Vorpolitische Grundlagen des demokratischen Rechtsstaates? (Fundamentos prepolíticos del Estado democrático de Derecho?), en: Jürgen Habermas / Joseph Ratzinger, Dialektik der Säkularisierung. Über Vernunft und Religion (Dialéctica de la secularización. Sobre la razón y la religión), Freiburg: Herder 2005, pp. 15-37, especialmente p. 31 sq. 
HABERMAS Jürgen y Jacques Derrida (2006), Filosofía en tiempos de terror, Hamburgo.

KÚNG, Hans (2006), Der Islam. Geschichte, Gegenwart, Zukunft (El Islam. Historia, presente, futuro), Munich-Zurich: Piper.

MAIER, Hans (2002), Welt ohne Christentum - was wäre anders? (El mundo sin el cristianismo - cuál sería la diferencia?), Freiburg etc.: Herder.

MITIAS, Michael H. (1991), Challenges of Universalism, en: DIALOGUE AND HUMANISM. THE UNIVERSALIST QUARTERLY (Varsovia), vol. I, No 1, primavera de 1991, pp. 5-15; M. B. Ramose, Hegel and Universalism: An African Perspective, en: ibíd.

MITZMAN, Arthur Mitzman (1976), La jaula de hierro. Una interpretación histórica de Max Weber, Madrid: Alianza.

MOLS, Manfred (1975), Zum Problem des westlichen Vorbildes in der neueren Diskussion zur politischen Entwicklung (Sobre el problema del prototipo occidental en la nueva discusión en torno al desarrollo político), en: VERFASSUNG UND RECHT IN ÜBERSEE, vol. 8 (1975), Nº 1, p. 5.

MOMMSEN, Wolfgang (1974) Universalgeschichtliches und politisches Denken (Pensamiento histórico universal y político), en: W. Mommsen, Max Weber. Gesellschaft, Politik und Geschichte (Max Weber. Sociedad, política e historia), Frankfurt: Suhrkamp 1974.

MOMMSEN, Wolfgang (1974), Ein Liberaler in der Grenzsituation (Un liberal en la situación límite), en: W. Mommsen, 1974. (nota 6), Wolfgang Mommsen, Zum Begriff der "plebiszitären Führerdemokratie" (Sobre el concepto de la "democracia caudillista plebiscitaria"), en: W. Mommsen, 1974 (nota 6), especialmente p. 48 sq.;

MOMMSEN, Universalgeschichtliches..., 1974 (nota 6), p. 126 sq.

MUGUERZA, Javier et al. (1989), El fundamento de los derechos humanos, Madrid: Debate 1989.

PIPES, Richard (2002), Propiedad y libertad. Dos conceptos inseparables a lo largo de la historia, Madrid / México: Turner / FCE.

RATZINGER, Joseph (Benedicto XVI), Was die Welt zusammenhält. Vorpolitische moralische Grundlagen eines freiheitlichen Staates (Lo que 
sostiene el mundo. Fundamentos morales prepolíticos de un Estado liberal), en: Habermas / Ratzinger, op. cit. (nota 18), p. 47.

ROCHE CÁRCEL, Juan A. (comp.) (2007) Espacios y tiempos inciertos de la cultura, Barcelona: Anthropos.

RODINSON, Maxime (1987), Islamischer Patrimonialismus: ein Hindernis für die Entstehung des modernen Kapitalismus? (El patrimonialismo islámico: un obstáculo para el surgimiento del capitalismo moderno?), en: Wolfgang Schluchter (comp.), Max Webers Sicht des Islams. Interpretation und Kritik (La visión de Max Weber sobre el Islam. Interpretación y crítica), Frankfurt: Suhrkamp 1987.

SCHLUCHTER, Wolfgang (1979), Die Entwicklung des okzidentalen Rationalismus. Eine Analyse von Max Webers Gesellschaftsgeschichte, Tübingen: Mohr-Siebeck 1979.

SCHULZE, Gerhard (2004) Die beste aller Welten. Wohin bewegt sich die Gesellschaft im 21. Jahrhundert? (El mejor de los mundos. Adónde se mueve la sociedad en el siglo XXI), Frankfurt: Fischer.

SENGHAAS, Dieter (1998), Zivilisierung wider Willen. Der Konflikt der Kulturen mit sich selbst (Civilización contra la propia voluntad. El conflicto de las culturas consigo mismas), Frankfurt: Suhrkamp.

SENGHAAS, Dicter (1998) Ziviliewing wider Willen. Der Konflikt der Kulturen mit sich selbat (Civilización contra la propia voluntad. El conflicto de las culturas consigomismos) Frankfurt: Suhekamp 1998.

SOROUSH, Abdolkarim (2000) Reason, Freedom, and Democracy in Islam, Oxford: Oxford U. P.

WALDMANN, Meter (2006), El Estado anómico. Derecho, seguridad pública y vida cotidiana en América Latina, Madrid: Iberoamericana 2006.

WEBER, Max (1968), Vom inneren Beruf zur Wissenschaft (Sobre la vocación para la ciencia) [1919], en: Max Weber, Soziologie, weltgeschichtliche Analysen, Politik (Sociología, análisis de la historia universal, política), compilación de Johannes Winckelmann, Stuttgart: Kröner. 
WEBER, Max (1920/1921), Gesammelte Aufsätze zur Religionsphilosophie (Ensayos reunidos sobre sociología de la religión), Tübingen: MohrSiebeck.

WEBER, Max (1995), Der Sozialismus (El socialismo) [1920], edición anotada de Herfried Münkler, Weinheim: Beltz Athenäum 1995, passim; Gernot Volger, Max Weber und der Sozialismus (Max Weber y el socialismo), en: LIBERAL (Bonn), vol. 38, $\mathrm{N}^{\mathrm{o}}$ 1, febrero de 1996, pp. 111-114.WOOD, Charles H. / Bryan R. Roberts (comps.) (2005), Rethinking Development in Latin America, University Park: Pennsylvania State U. P. 2005.

WITTFOGEL Karl A. (1977), Die orientalische Despotie. Eine vergleichende Untersuchung totaler Macht (El despotismo oriental. Una investigación comparativa del poder total), Frankfurt / Berlin: Ullstein.

WÖHLCKE, Manfred (1996), Soziale Entropie. Die Zivilisation und der Weg allen Fleisches (Entropía social. La civilización y el camino de toda carne), Munich: dtv.

Envío 15 de julio /2010 - aceptación 4 de septiembre /2010 